\title{
ATTITUDES OF WOMEN TO MENOPAUSE: IMPLICATIONS FOR COUNSELLING
}

\author{
OSARENREN, N, PhD \\ UBANGHA, M.B, PhD \\ NWADINIGWE, I.P PhD \\ $\&$ \\ OGUNLEYE, T, PhD. \\ Department of Educational Foundations \\ University of Lagos \\ Lagos - Nigeria \\ email: ngoziosarenren@yahoo.com
}

\begin{abstract}
Menopause, a normal midlife transition for women remains poorly understood. This study examined the attitudes of women to menopause. A total of 300 married female teachers made up the sample for the study. Data was collected using the modified Attitude Towards Menopause (ATM) checklist. The responses of the participants were analyzed using simple percentages. The results showed that an overwhelming majority of the respondents indicated concern about how their husbands will feel about them after menopause (98\%); women should see a doctor at menopause (91\%); menopause is an unpleasant experience (83\%) among others. The implications these findings have for counselling and counsellors were discussed. The focus was on the key strategies the counsellor should adopt in helping women to cope with menopause and also develop positive attitudes toward it.
\end{abstract}

Key Words: Menopause; Attitudes, Midlife; Aging; Counselling; Assertiveness training; Cognitive re-structuring; Values clarification.

\section{Introduction}

African society is much more permissive of aging in men. Most positive traits associated with masculinity actually increase with age e.g. competence, autonomy, self-control and power, whereas feminine characteristics such as sweetness, passivity, non-competitiveness and gentleness usually remain stable as women age. Again, women's wisdom is considered to be age-old intuitive knowledge about the emotions therefore aging is believed to have added nothing to feminine knowledge. 
But men valued for their rational, intellectual minds, actually benefit from aging because experience tends to increase this type of knowledge.

Schroots \& Birren (1990) contend that aging may be regarded as a process of progressive "desynchronization" of the human system in its environment, nevertheless within this process, the striving for synchronization and order is maintained. Saucier (2004) also explained that problems related to a woman's realization that she no longer conforms to society's standards of youth and beauty include low selfesteem, depression and anxiety. These problems are basically because women seem to be more vulnerable than men to the pressure from society to conform to its expectations and as a result face more questions of self-worth as they enter the middle years of their life. Menopause is a landmark event during this period.

Kelly (2001) views aging as a process that is largely genetically controlled; in as much as there are wide individual differences each of us experience a gradual process of slowing down and becoming physically less pliable. The female body is genetically programmed to cease menstruating sometime in middle age usually but not strictly between the ages of 45 and 55. This is called menopause and the years surrounding this period are usually termed perimenopause. There is no typical perimenopause. Some of the common symptoms include:

- Memory lapses and loss of concentration

- $\quad$ Headaches - this may be caused by fluctuating hormone levels

- Mood swings - changes in hormone levels may actually interfere with the production of mood regulator serotonin

- Dry skin - this is due to decrease in the protein collagen

- Bone loss - declining reproductive hormones translates to less protection for bones. This is actually at its worse after menopause.

- Hot flashes - period of intense warmth, flushing and perspiration

- $\quad$ Erratic menstrual cycles - this may vary from 18 days to missed periods. Excessive bleeding is also common. A woman can still become pregnant.

- Vaginal dryness - vaginal wall thins and becomes less elastic

- Urinary incontinence - as the vaginal wall weakens the bladder loses support and urination is harder to control

- Weight gain 
- Some women also report depression, irritability and other emotional problems (Perz, 1997; Ditkoff, Crary \& Lobo, 1991; Ballinger, 1990 \& Morse et al, 1994).

Menopause is a natural transition all women experience as natural as adolescence. How a woman experiences menopause is determined by many factors: attitude, diet, overall health, genetics and cultural group. But the fact remains that menopause is a universal female midlife transition that remains poorly understood (Huffman \& Myers, 1999). In the same vein, Huffman et al (2005) concedes that menopause is multidimensional influenced by biological, psychological and sociocultural factors and requires responses that are equally multidimensional.

Sommer et al (1999) investigated the degree to which attitudes toward menopause and aging vary across ethnic groups and menopausal status. A sample of more than 16,000 women indicated women's attitudes toward menopause ranged from neutral to positive; with African American women indicating significantly more positive attitude to menopause. Nevertheless, Dennerstein et al (1994) had observed that positive attitudes toward menopause are associated with positive experiences of menopause whereas negative attitudes are associated with both negative symptoms and negative experiences. In furtherance of this Bowles (1986) maintained that attitudes influence menopausal experience. This contention implies that the attitude of the woman towards menopause will invariably influence her experience of menopause. Therefore, women should be encouraged to develop positive attitude towards menopause. In addition, much of how a woman's life is affected by menopause depends to a great extent on how she views herself (Lippert, 1997; Greenwood, 1992). Because women are often judged on the basis of their appearance and youthfulness, those who have used their glamour to attract men and enhance their self-esteem may find aging particularly painful (Strong et al, 2002; Kelly, 2001).

From the foregoing, it becomes clear that women are concerned about aging and its implications for them especially psychologically. But the key issue is acceptance of the inevitability of the aging process. Acceptance can lead to more positive feelings about self and to a high level of satisfaction with one's life circumstances (Saucier, 2004). Women can therefore be guided to begin to think of midlife as a time for reevaluation, not crisis. In fact, they should be encouraged to become more realistic and to reappraise their goals and their ability to meet such goals (Mackin, 1995). 
It is against this background that this study examines the attitude of women to menopause and at the same time explaining the critical role counsellors should play in enhancing the understanding and acceptance of menopause by women. The justification for this study therefore hinges on the need to properly articulate the attitudes of women toward menopause.

\section{Method}

The population of interest for this study included women between the ages of 40 and 50. A convenient sample was recruited using a snowball sampling technique (Jones, 1997) in which identified participants suggested other women whom they believed would also take part in the study. Although participants were from different ethnic groups in Nigeria, they were recruited from among the students during the 2006 Long Vacation Programme (Sandwich Programme) for teachers. The researchers taught a compulsory course during this period and had access to many of the participants. Of the 350 distributed questionnaires, 300 were valid for a response rate of $85.7 \%$.

The participants were a heterogeneous sample in terms of age, marital status and education. All the participants were married with the average age at the time of marriage being 22 years, and they had been married for at least 18 years. They were all qualified teachers with National Certificate in Education (NCE) with an average of 15 years teaching experience and were currently teaching in either public or private secondary schools as at the time of this study; and they were all in the final year of the five-year programme. Twenty-six point seven (80) are between ages $40-43 ; 50 \%$ (75) $44-47$ years and $23.3 \%$ (70) $48-50$ years.

The instrument used for the study is the Attitude Towards Menopause (ATM) checklist developed by Neugarten et al (1963) and modified by Huffman et al (2005). The ATM was modified and adapted; three items were dropped from the 22-items i.e. (1) "A woman has a broader outlook on life after the change", (2)"Women worry about losing their minds during the menopause", (3) "Women often use the change of life as an excuse for getting attention". All items that had "change of life" were changed to "menopause". The item "it is no wonder women feel "down in the dumps" at the time of menopause" was modified to read "women usually feel "down in the dumps" at the time of menopause". For this study the modified ATM Checklist had 19 items. The split-half reliability value for the ATM for this study is 0.86 . 


\section{Results/Discussion}

The responses of the respondents were analyzed using simple percentage. The result is as shown in table 1.

Table 1: Percentage of Respondents Indicating "Agree" or "Strongly Agree" on the Attitudes Toward Menopause Checklist

\begin{tabular}{|c|c|c|}
\hline & Statement & \% Agreement \\
\hline 1. & $\begin{array}{l}\text { A woman is concerned about how her husband will feel } \\
\text { about her after menopause. }\end{array}$ & 98.30 \\
\hline 2. & A woman should see a doctor at menopause. & 90.82 \\
\hline 3. & $\begin{array}{l}\text { Menopause is one of the biggest changes that happens } \\
\text { in a woman's life. }\end{array}$ & 87.60 \\
\hline 4. & Menopause is an unpleasant experience. & 82.65 \\
\hline 5. & $\begin{array}{l}\text { After menopause a woman feels freer to do things for } \\
\text { herself }\end{array}$ & 75.00 \\
\hline 6. & $\begin{array}{l}\text { Women think of menopause as the beginning of the } \\
\text { end. }\end{array}$ & 78.50 \\
\hline 7. & Women generally feel better after menopause. & 71.75 \\
\hline 8. & $\begin{array}{l}\text { Frankly speaking, just about every woman is depressed } \\
\text { about menopause. }\end{array}$ & 68.75 \\
\hline 9. & $\begin{array}{l}\text { Women are generally calmer and happier after } \\
\text { menopause. }\end{array}$ & 65.25 \\
\hline 10. & $\begin{array}{l}\text { Menopause is a disturbing thing that women generally } \\
\text { dread. }\end{array}$ & 62.88 \\
\hline 11. & $\begin{array}{l}\text { Women should expect some troubles during } \\
\text { menopause }\end{array}$ & 60.75 \\
\hline 12. & $\begin{array}{l}\text { A woman's body may change in menopause but } \\
\text { otherwise she doesn't change much. }\end{array}$ & 60.35 \\
\hline 13. & $\begin{array}{l}\text { Women usually feel "down in the dumps" at the time } \\
\text { of menopause }\end{array}$ & 58.88 \\
\hline 14. & Life is more interesting for a woman after menopause & 58.20 \\
\hline 15. & $\begin{array}{l}\text { After menopause, women do not consider themselves } \\
\text { "real women" }\end{array}$ & 57.00 \\
\hline 16. & $\begin{array}{l}\text { Changes inside the body that women cannot control } \\
\text { cause all the trouble at menopause }\end{array}$ & 56.80 \\
\hline 17. & $\begin{array}{l}\text { The only difference between a woman who has been } \\
\text { through menopause and one who has not is that one } \\
\text { menstruates and the other doesn't }\end{array}$ & 53.92 \\
\hline 18. & $\begin{array}{l}\text { Going through menopause really does not change a } \\
\text { woman in any important way. }\end{array}$ & 53.00 \\
\hline 19. & $\begin{array}{l}\text { A woman gets more confidence in herself after } \\
\text { menopause. }\end{array}$ & 42.65 \\
\hline
\end{tabular}


Evidence from the table shows the total percentage scores of agreement with each of the 19 statements about menopause on the adapted ATM rank ordered by frequency of response. Almost all (98.3\%) of the respondents are concerned with how their husbands will feel about them after menopause. Some of the respondents through personal interactions with the researcher confirmed that they actually came back to school to reassure themselves of their self- worth. And this was due to feelings of low self- esteem at the onset of menopause. It is interesting to note that education and personal income did not insulate these women from expressing this deep concern with how their husbands feel about them after menopause. This also may explain why the lowest score by the respondents on the ATM $(42.65 \%)$ was that a woman gets more confidence in herself after menopause. If actually a woman gets more confidence in herself then an overwhelming majority of them will not have indicated concern on how their husbands feel. This shows that the need for a woman to have an understanding husband whom she shares closeness with will reduce her vulnerability to the psychological issues associated with aging and menopause. In fact, Whiffen (2005) and Eckstein et al (2006) found that individuals who avoid closeness with and/or devalue spouses are perceived as unresponsive to spouses' vulnerability. This perception increases the spouse's attachment security and depressive symptoms. This, therefore, implies that any deprecating attitude from the spouse of a menopausal woman will possibly affect the ability to handle the issues emanating from perimenopause.

It is gladdening to observe that about $91 \%$ of the respondents indicated that a woman should see a doctor at menopause. If actually women will take the bold step of seeing a doctor at menopause it will go a long way in helping their understanding of what menopause entails. At least the doctor will explain the symptoms associated with perimenopause and some of the temporary discomforts they may experience. Above all, this is particularly important since about $83 \%$ of the respondents consider menopause as an unpleasant experience and $69 \%$ conclude that every woman is depressed about menopause. The perception of menopause in this negative context by these respondents confirms Bowles (1986) opinion that attitudes influence menopausal experience.

Although, about $63 \%$ of the respondents indicate that menopause is a disturbing thing that women generally dread, $72 \%$ acknowledge that women generally feel better after menopause while $65 \%$ agree that women are generally calmer and happier after menopause. The critical 
issue here is that there should be emphasis on positive perception of menopause. Therefore, these respondents should be encouraged because much of how a woman's life is affected by menopause depends on how she views herself. In other words, the woman's self-concept is a central issue in understanding her attitudes or perception of menopause. Fiftyseven percent of the respondents indicate that after menopause, women do not consider themselves "real women". This expression of low selfesteem is not psychologically healthy for a woman experiencing midlife crisis. However, $54 \%$ agree that the only difference between a woman who has been through menopause and one who has not is that one menstruates and the other doesn't and 53\% concede that going through menopause really does not change a woman in any important way. But in as much as this position is not in congruence with the earlier contention of women not considering themselves as "real women", it should not be ignored. It is a red alert sign that must be taken seriously in the understanding of women's perception of menopause.

From the discussion thus far it is very clear that the perception of menopause is distorted and skewed. Therefore there is need for intervention for proper understanding of the key issues underlying menopause as an aspect of aging among women.

\section{Implications for Counselling and Counsellors}

The findings in this study have obvious implications for counselling. Counsellors need to develop an awareness of the interaction of individual, biological and socio-cultural influences on women in midlife. This awareness will equip the counsellor to come to terms with the inevitability of focusing on resolving developmental conflicts among women in this group.

Counsellors should use the technique, construction of meaning. According to Lippert (1997) this meaning - making process involves several strategies including consideration of any broader psychological issues, analysis of the nature of events in the lives of these women and their meaning, empowerment through support, affirmation of commitments and self-exploration. Women can therefore be guided through the process of group counselling to begin to think of midlife as a time for re-evaluation not crisis. Similarly, counsellors should facilitate the process of helping women to learn to value themselves for who they are and for their inner selves.

Values clarification is another process which can help women realize that incongruence of values with behaviour and circumstances can cause conflicting emotions about their ideas of who they really are. She 
should therefore be assisted in developing internalized values that will support her through the aging process. In fact, Howell (2001) opined that when women's values were congruent with their behaviours and circumstances, they reported feeling happy, satisfied and comfortable; whereas incongruence in these areas resulted in feelings of guilt, sadness, anger, anxiety, fear and loneliness. Nevertheless, the positive aspect of the negative feelings is that this should be seen as an impetus for a woman to begin the process of assessing changes in her environment.

The use of metaphor is also advocated as a valuable tool to help women create a more positive attitude toward aging and menopause. Clark \& Schwiebert (2001) proposed the use of Penelope's Loom, a Greek myth. The Loom helps the client see that each life is unique with myriad threads coming together to form a life tapestry. These threads may include menopause, intimate relationships and multiple roles and expectations. The counsellor can help a woman unravel and re-weave her tapestry in midlife.

Finally, assertiveness training and cognitive restructuring will be very effective in helping a woman to develop resistance to external influences that influence her perception of herself as a valued member of society. This is predicated on the finding whereby more than half of the respondents $(57 \%)$ indicate that after menopause women do not consider themselves "real women". Secondly, about 79\% think of menopause as the beginning of the end.

\section{References}

Ballinger, C. B. (1990). Psychiatric aspects of menopause. British Journal of Psychiatry, 156, 773 - 787.

Bowles, C. (1986). Measure of attitude toward menopause using the semantic differential model. Nursing Research, 35, 81 - 85.

Clark, S. H. \& Schwiebert, V. L. (2001). Penelope's Loom: A metaphor of women's development at midlife. Journal of Humanistic Counselling, Education and Development, 40, $161-169$.

Dennerstein, L., Smith, A. \& Morse, C. (1994). Psychological well-being, mid-life and the menopause. Maturitas, 20, $1-11$.

Ditkoff, E. C., Crary, W. G., Cristo, M. \& Lobo, R. A. (1991). Estrogen improves psychological function in a symptomatic postmenopausal women. Obstetrics \& Gynecology, 78, 991 - 995.

Eckstein, D., Clemmer, F. \& Fierro, A. (2006). The use of image exchange in examining relationship role perceptions. The Family Journal: Counselling Therapy for Couples and Families, 14 (1), 71 - 76. 
Greenwood, S. (1992). Menopause naturally: Preparing for the second half of life. Volcano, CA: Volcano Press.

Howell, L. C. (2001). Implications of personal values in women's midlife development. Counselling $\mathcal{E}$ Values, 46, $54-65$.

Huffman, S. B. \& Myers, J. E. (1999). Counselling women in midlife: An integrative approach to menopause. Journal of Counselling Development, 77, 258 - 266.

Huffman, S. B., Myers, J. E., tingle, L. R. \& Bond, L. A. (2005). Menopause symptoms and attitudes of African American women: Closing the knowledge gap and expanding opportunities for counsellor. Journal of Counselling $\mathcal{E}$ Development, 83(1), 48 - 56.

Jones, J. B. (1997). Representations of menopause and their health care implications: A qualitative study. American Journal of Preventive Medicine, 13, 58 - 65.

Kelly, G. F. (2001). Sexuality today: The human perspective (7th ed). New York: McGraw-Hill.

Lippert, L. (1997). Women at midlife: Implications for theories of women's adult development. Journal of Counselling and Development, $76,16-22$.

Mackin, J. (1995). Women, stress and midlife. Human Ecology Forum 23(4), $20-22$.

Morse, C. A., Smith, A., Dennerstein, L., Green, A., Hopper, J. \& Burger, H. (1994). The treatment-seeking woman at menopause. Maturitas, $18,161-173$.

Neugarten, B. L., Wood, V., Kraines, R. J. \& Loomis, B. (1963). Women's attitudes toward menopause. In B. L. Neugarten (Ed) Middle age and ageing: A reader in social psychology (pp. 195 - 201). Chicago: University of Chicago Press.

Perz, J. M. (1997). Development of menopause symptoms list: A factor analysis study of menopause associate symptoms. Women and Health, 25, 53 - 69 .

Saucier, M. G. (2004). Midlife and beyond: Issues for aging women. Journal of Counselling and Development, 82(4), 420 - 425.

Schroots, J. J. \& Birren, J. E. (1990). Concepts of time and aging in science. In J. E. Birren \& K. W. Schaie (Eds) Handbook of the psychology of aging (3rd ed, pp. 45 - 64). San Diego, CA: Academic Press.

Sommer, B., Avis, N., Meyer, P., Ory, M., Madden, T., Kaggwa-Singer, M., Mouton, C., Rasor, N. O. \& Adler, S. (1999). Attitudes toward menopause and aging across ethnic/racial groups. Psychosomatic Medicine, 61 (6): $868-875$. 
Strong, B., Devault, C., Sayad, B. W. \& Yarber, W. L. (2002). Human sexuality: Diversity in contemporary America (4th ed.) New York: McGraw-Hill.

Whiffen, V. E. (2005). The role of partner characteristics in attachment insecurity and depressive symptoms. Personal Relationships, 12(3), $407-424$. 